\title{
KOSULYS OTORINOLARINGOLOGO POŽIŪRIU
}

DOC. DR. RŪTA PRIBUIŠIENĖ, PROF. HABIL. DR. VIRGILIJUS ULOZAS

KMU AUSŲ, NOSIES IR GERKLE்S LIGŲ KLINIKA

Reikšminiai žodžiai: kosulys, gastroezofaginio refliukso liga, gerklų paralyžius, sinusitas, nosies polipozė, išorinės ausies ligos. Santrauka. Nustatant kosulio priežastį neretai bendradarbiauja kelių specialybių gydytojai. Kadangi kosuli gali provokuoti viršutiniuose kvejpavimo takuose (ryklejje, gerklose) esančių refeksinių sričių dirginimas, svarbu otorinolaringologinis paciento tyrimas. Otorinolaringologai gali patvirtinti ar atmesti daugeli kosulio priežasčių: gastroezofaginio refliukso ligos laringofaringinę formą, gerklų darinius, svetimkūnius ar balso klosčių paralyžių, nosies ir prienosinių ančių bei išorinės klausomosios landos ligas. Tik kompleksinis priežastinis gydymas garantuoja laukiamą stabilų gydymo efektą.

\section{IVADAS}

Kosulys - vienas iš nusiskundimų, kurio priežasčiai patikslinti reikalingas otorinolaringologinis tyrimas. Vieni pacientai ausų, nosies, gerklès ligų specialisto konsultacijos būna siunčiami kitų specialybių gydytojų, kiti kreipiasi patys - pastarieji kosuli nurodo tarp kitų otorinolaringologinių simptomų. Bene dažniausiai ieškant kosulio priežasties tenka bendradarbiauti su pulmonologais.

Tiriant kosuliu besiskundžiantị pacientą, svarbu nustatyti šio simptomo priežastị. Tik tokiu atveju galima tikètis, kad gydymas bus veiksmingas ir ligos eiga palanki. Žinoma, kad kosulị gali sukelti ne tik apatinių kvėpavimo takų ligos, bet ir viršutiniuose kvėpavimo takuose esančių refleksogeninių zonų bei išorinès klausomosios landos dirginimas [1-3]. Šiuo atveju kosulys kyla dèl refleksinio atsako i pokyčius klajoklio nervo inervuojamose gleivinèse (ryklès, gerklų) ar odoje (išorinès klausomosios landos). Refleksogenines ryklès ir gerklų zonas gali pasiekti dirgikliai iš artimiausios aplinkos, dažniausi - išskyros iš nosies, nosiaryklès bei skrandžio sulčių refliuksas. Pirmuoju atveju neretai priežastis yra lètinis rinosinusitas su polipoze ar be jos, antruoju - gastroezofaginio refliukso liga (GERL).
Refleksinị kosulị sąlygojantis dirginimas gali būti ūmus, periodinis ir nuolatinis. I burnaryklę ar gerklas patekęs svetimkūnis (kietas, skystas) sukelia ūmų, neretai gerklų spazmo lydimą kosulį. Periodiškai kvėpavimo takų refleksines zonas gali dirginti iš nosiaryklès ar stemplès ištekantis sekretas. Nuolatinis refleksinis kosulys neretai kyla dèl darinio gerklarykleje ar gerklose (polipas, cista, granuloma), kakle (padidejęs limfmazgis, cista, skydliaukès mazgas), gleivinių sausumo (anemija, cukrinis diabetas, eksikozè), aspiracijos. Aspiraciją dažniausiai lemia neurologinès priežastys, iš jų nemažą reikšmę turi sutrikęs gerklų judrumas (balso klosčių paralyžius), padidėjęs seilètekis arba šių būklių derinys [4]. Nuolatini ar periodinị refleksinị kosulị gali sąlygoti ir išorinès klausomosios landos dirginimas.

Otorinolaringologo vaidmuo tiriant kosuliu besiskundžiantị pacientą yra toks: žinoti, diagnozuoti ir kompleksiškai gydyti kosulį sukèlusius priežastinius sutrikimus. Neabejotinai sėkmingą gydymą lemia bendradarbiavimas su kitų sričiu specialistais (alergologais, gastroenterologais, endokrinologais ir kt.).

Pateiksime keletą dažniausiai kasdieniame darbe pasitaikančių otorinolaringologo diagnozuojamų refleksinio kosulio modelių. 


\section{KOSULYS IR GERL}

Kosulys tarp gastroezofaginio refliukso ligos (GERL) netipiniu simptomų minimas bene seniausiai. Tai buvo patvirtinta klinikinėmis studijomis $[5,6]$ bei vykusiais gastroenterologų ir kitų GERL klausimus nagrinėjančių specialistų sutarimais $[7,8]$.

Lietuvoje kalbèti apie GERL netipinę otorinolaringologinę raišką pradèta 1991 metais VII Lietuvos otorinolaringologų suvažiavime (V. Uloza). Pirmieji spausdinti darbai Lietuvos recenzuojamuose žurnaluose pasirodè $2000 \mathrm{~m}$. Vèliau ši tema buvo diegiama klinikinę praktiką skaitant pranešimus, paskaitas, atliekant ir skelbiant mokslinius darbus apie ligos klinikinius simptomus, diagnostikos ir gydymo metodu pritaikymą Lietuvos gydymo įstaigose [9]. 2007 metais vykusioje respublikineje Lietuvos otorinolaringologu konferencijoje nutarta otorinolaringologiniais simptomais pasireiškiančią GERL vadinti GERL laringofaringine forma (GERL LF). Konferencijoje priimtos ir Lietuvai adaptuotos diagnostikos ir gydymo nuorodos $[10,11]$.

GERL LF skiriasi nuo tipinès ligos formos patogeneze, klinikiniais požymiais, diagnostika ir gydymu (1 lentelè).

GERL LF atveju morfologinius pokyčius ir funkcinius sutrikimus ryklejje ir gerklose sukelia viršstemplinis bei stemplinis gastroezofaginis refliuksas (GER). Stemplinis GER lemia stemplinių simptomų (rèmens, šleikštulio) atsiradimą bei refleksiškai gali skatinti atsirasti kosuli, kaklo raumenų įtampą. Viršstemplinis GER (dar vadinamas gastrofaringiniu refliuksu) dèl tiesioginio poveikio ryklès ir gerklų gleivinei sąlygoja nestemplinių simptomų (krenkštimo, užkimimo, kosulio, „kąsnio“ gerkleje ir kt.) genezę. Pastariesiems būdingas lètinis pasikartojantis pobūdis, daugybiškumas. Diagnostikai svarbūs daugiau nei 1 mèn. besikartojantys simptomai $[5,6,10]$.

Kosulys yra vienas dažniausių nestemplinių GERL simptomų. Literatūros duomenimis, 43 proc. atvejų vienintelè lètinio kosulio priežastis yra GERL. Apie 75 proc. GERL sukelto kosulio pacientu gali neturèti kitų GERL simptomų. GERL sukelto kosulio diagnozė patvirtinama, kai kosuli efektyviai slopina specifinis antirefliuksinis gydymas [12]. Kosulio reikšmę GERL diagnostikai pagrindè D. Book su kolegomis (2001), apibendrinę 415-os JAV ORL ìstaigų duomenis. Jie nurodè, kad esant keturių nestemplinių simptomų deriniui (užkimimas, krenkštimas, „kąsnio“ pojūtis, lètinis kosulys), GERL LF teisingai diagnozuojama 95-98 proc. atvejų [5]. Šiam teiginiui neprieštarauja ir KMUK studijų rezultatai [6].

Refliuksinis laringitas (RL) - būdingiausia GERL LF išraiška. RL pasireiškia visų gerklų dalių įvairaus laipsnio paburkimu, paraudimu ir hipertrofija (1 pav.). Aktyvesnè acidifikacija ar šarminis refliuksas gali sąlygoti granulomų susidarymą (2 pav.) ar net gerklų

\begin{tabular}{|c|c|c|}
\hline Požymiai & Tipinė GERL & GERL LF \\
\hline \multicolumn{3}{|l|}{$\underline{\text { Simptomai }}$} \\
\hline Rèmuo ir/ar atpylimai & ++++ & + \\
\hline $\begin{array}{l}\text { Užkimimas, krenkšti- } \\
\text { mas, „kąsnis“, kosulys, } \\
\text { ryklës peršèjimas }\end{array}$ & + & ++++ \\
\hline \multicolumn{3}{|l|}{ Tyrimai } \\
\hline $\begin{array}{l}\text { Ezofagitas } \\
\text { Stemplès motorikos }\end{array}$ & ++++ & + \\
\hline $\begin{array}{l}\text { sutrikimas } \\
\text { Stemplès apsivalymo }\end{array}$ & +++ & + \\
\hline (klirenso) sutrikimas & +++ & + \\
\hline Gerklų pokyčiai & + & ++++ \\
\hline \multicolumn{3}{|l|}{$\underline{\text { Refliukso tipas }}$} \\
\hline Naktinis & ++++ & + \\
\hline Dieninis & + & ++++ \\
\hline Mišrus & + & +++ \\
\hline \multicolumn{3}{|l|}{ Atsakas i gydymą } \\
\hline $\begin{array}{l}\text { koregavimas } \\
\text { Sèkmingas gydymas }\end{array}$ & ++ & + \\
\hline $\begin{array}{l}\text { PSI*1 k./d. } \\
\text { Sèkmingas } \quad \text { gydymas }\end{array}$ & +++ & + \\
\hline $\mathrm{PSI}^{*} 2 \mathrm{k} . / \mathrm{d}$. & ++++ & +++ \\
\hline
\end{tabular}

epitelio displaziją. Manoma, kad patologinis GER lemia du trečdalius gerklų-ryklès ligų ir yra reikšmingas kofaktorius gerklų ir ryklès vèžio patogenezèje [13].

Diagnozuojant ir gydant GERL LF dažniausiai dalyvauja šeimos gydytojai, otorinolaringologai bei gastroenterologai (3 pav.). Diferencijuojant galimą simptomų kilmę, neretai pacientas konsultuojamas ir pulmonologų-alergologų. Kartais diagnozei pagrịsti reikalingas ir histologinis stemplès bioptato tyrimas, kurio diagnostinè nauda per menkai vertinama. Nustatyta, kad GERL atveju stemplès biopsijos diagnostinis jautrumas yra 76 proc., specifiškumas - 85 proc. [14]

Nustatant GERL LF vertingas vieno mènesio diagnostinis gydymas standartine protonu siurblio inhibitoriu (PSI) doze (omeprazolio $20 \mathrm{mg}$ ) 2 kartus per parą. Jei diagnostinis gydymas veiksmingas, GERL LF galima diagnozuoti ir be kitų invazinių tyrimų [11]. Reikia atminti, kad diagnostini gydymą PSI galima skirti tik jaunesniems nei $45 \mathrm{~m}$. asmenims, neturintiems „grèsmingų“ simptomų, kuriems GERL simptomai išryškèja pirmą kartą [7, 8, 10, 11].

Gydant GERL LF laikomasi „step down“ principo. Gydymas pradedamas nuo protonų siurblio inhibitorių. Pagal užsienio šalių rekomendacijas bei Lietuvos otorinolaringologų bei gastroenterologų sutarimą PSI vartojami standartine doze, t. y. po $20 \mathrm{mg}$ omeprazolio (ar kitų PSI: lansoprazolio, esomeprazolio, rabeprazolio) 2 kartus per dieną $30 \mathrm{~min}$. prieš valgị ne mažiau kaip 3 mèn. [11, 15].

Neabejotinai reikšminga ir GERL LF simptomu pasireiškimo profilaktika, t. y. skirti PSI prieš operacijas, atliekamas endotrachejjinès nejautros sąlygomis, ilga- 


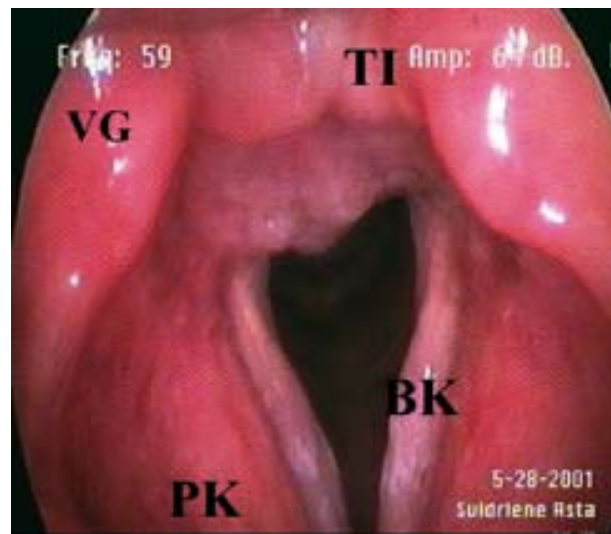

1 pav. REFLIUKSINIS LARINGITAS

Visu gerkly struktūru paburkimas, paraudimas, hipertrofija (KMU ANG ligu klinika, VLS)

VG - vedeginiai gumburai, TI - tarpvedegine išpjova

PK - prieangio klostès, BK - balso klostès.

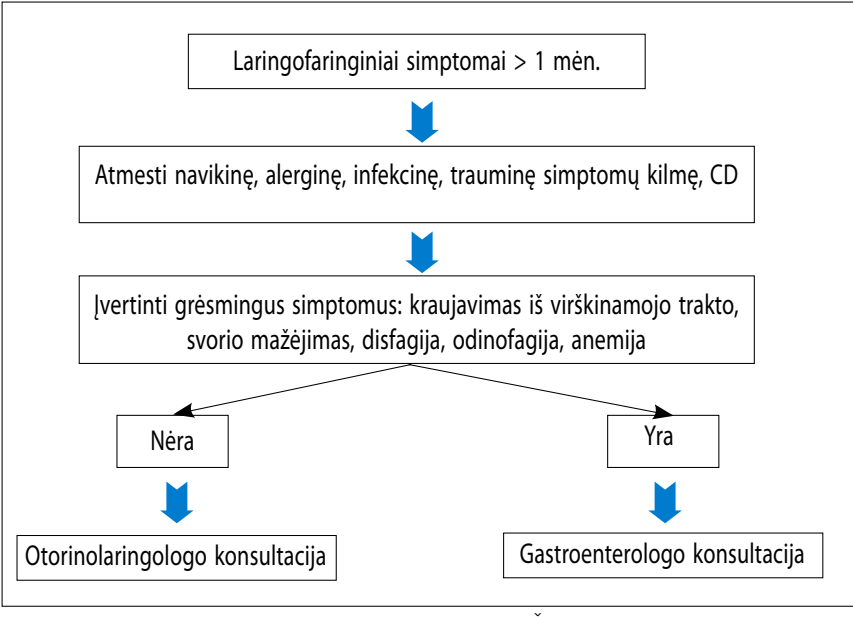

3 pav. PIRMINIS PACIENTUU, KURIEMS PASIREIŠKIA LARINGOFARINGINIŲ SIMPTOMŲ, IVERTINIMAS IR PASKIRSTYMAS

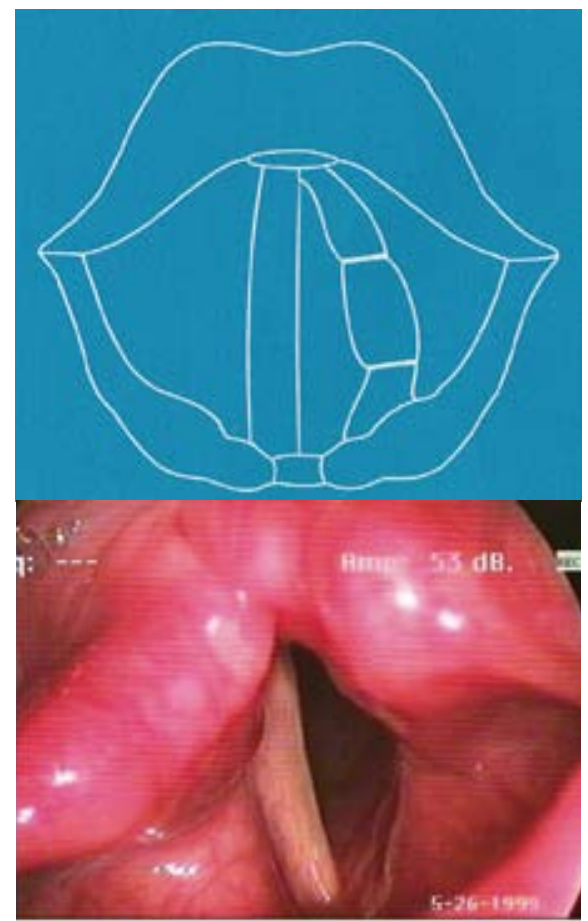

5 pav. KAIRIOSIOS BK LATEROFIKSACIJA

Schema ir laringoskopinis vaizdas (KMU ANG klinika)

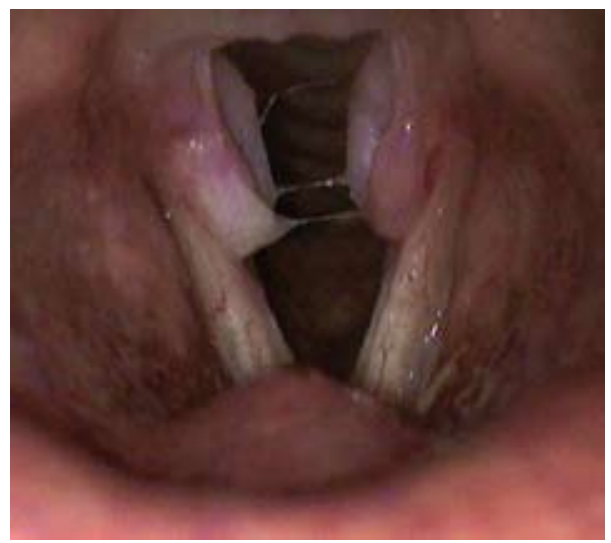

2 pav. KONTAKTINESS GRANULIOMOS ANT ABIEJŲ BALSO KLOSČIU UŽPAKALINIU TREČDALIU (KMU ANG LIGU KLINIKA, VLS)

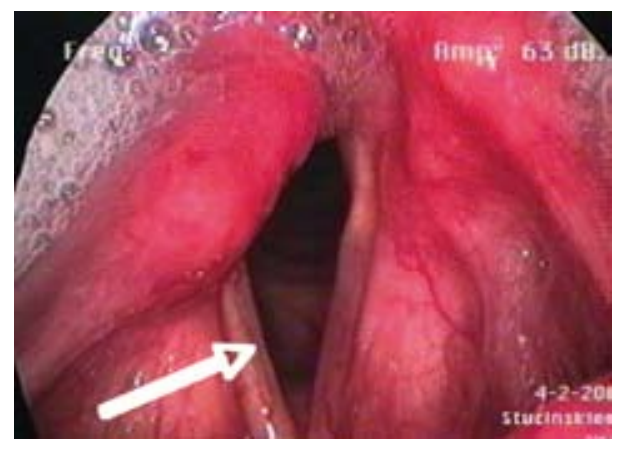

4 pav. VIENPUSIS GERKLŲ PARALYŽIUS Fonuojant dešinè balso klostè (rodyklè) lieka nejudri, stebimas seilių užtekèjimas i kvèpavimo takus.

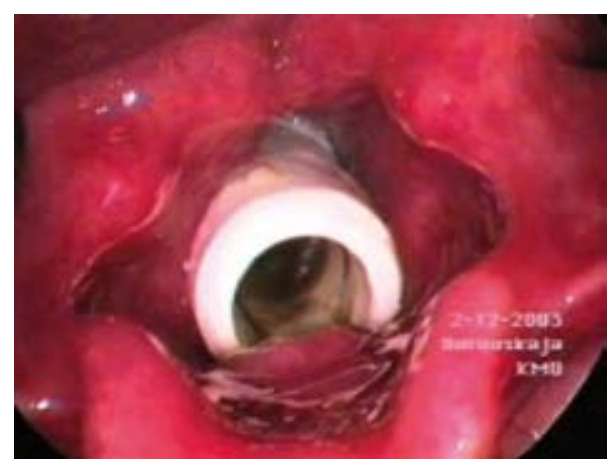

6 pav. GERKLU SPINDYJE ISTRIGĘS SVETIMKŪNIS (STENTAS)

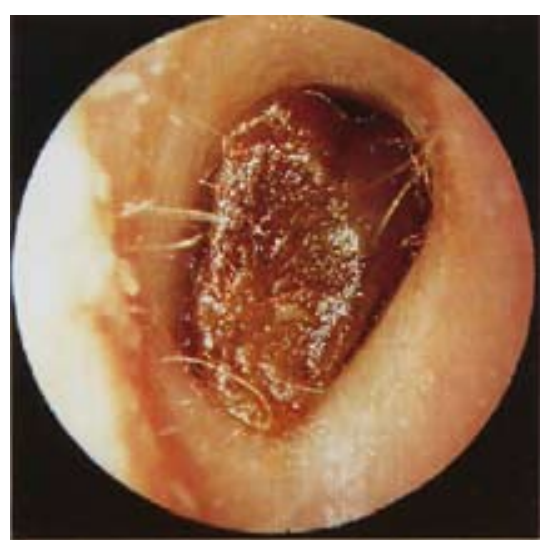

7 pav. SIEROS KAMŠTIS IŠORINĖJE KLAUSOMOJOJE LANDOJE 
laikès dirbtinès plaučių ventiliacijos metu, pacientams su nazogastriniu zondu ir kt. [11].

Išsami GERL LF diferencinė diagnostika, diagnostinių tyrimų seka, vertinimas, gydymas bei profilaktika pateikta 2008 m. išleistoje mokomojoje knygoje „GERL LF diagnostika ir gydymas“ bei "Medicinos“ žurnalo straipsniuose $[10,11]$.

\section{KOSULYS IR GERKLŲ PARALYŽIUS}

Gerklų judrumo sutrikimas neretai pasireiškia pakitusio balso, kosulio bei springimo deriniu. Šios patologijos priežastys paprastai trauminès (buka kaklo trauma, skydliaukès operacijos), neurogeninès (smegenų insultas, galvos smegenų trauma, operacija, sisteminès progresuojančios neurologinès ligos) ar navikinès (peraugęs ryklès, gerklų, stemplès vėžys, metastazès tarpuplaučio limfmazgiuose). Dėl minètų priežasčių išsivysto vienos ar abiejų pusių, viršutinio ar grị̌tamojo gerklų nervo (ar abiejų) neuropatija ir balso klosčių (BK) paralyžius. Simptomatika priklauso nuo ne tik nuo BK nejudrumo, bet ir nuo tarpo tarp jų kvejpuojant ir fonuojant (4 pav.). Jei BK nevisiškai susiglaudžia (vienpusis BK paralyžius), fonacijos metu girdimas užkimimas, dèl susilpnèjusio apsauginio reflekso pacientas springsta bei kosti, negali atsikosèti $[16,17]$.

Abipusio BK paralyžiaus atveju pacientą vargina inspiracinis dusulys. Šiuo atveju balsas gali būti pakitęs nedaug. Esant centrinès kilmès paralyžiui, simptomatiką papildo ir dẻl minkštojo gomurio nejudrumo pasireiškianti neaiški artikuliacija (atvirasis sniaukrojimas), maisto ir skysčių regurgitacija ị nosị [16].

Gerklų paralyžius diagnozuojamas ịvertinus anamnezę, nusiskundimus, balsą, kvėpavimą bei balso klosčių padèti ir judrumą. Sąmoningiems ligoniams gerklos apžiūrimos veidrodèliu (netiesioginè laringoskopija) bei gerklų endoskopu (vaizdo laringoskopija). Šiuo atveju pacientas turi aktyviai, valingai dalyvauti tyrime: iškišti liežuvị ir prisilaikyti, fonuoti balsę /a/. Nesąmoningiems ligoniams gerklų judrumą galima ịvertinti fibroskopija, endoskopą ịkišus pro nosį [16].

Gerklų paralyžius pusę metų gydomas konservatyviai: antineuritiniais vaistais, fonopediniu mokymu, gerklų elektrine stimuliacija [16]. Jei po pusès metu balso kokybė vis dar nepakankama, rekomenduojamos nejudrią BK prie judriosios priartinančios operacijos: BK plastika naudojant paciento riebalus ar tiroplastika (BK medializacija) [17]. Esant inspiraciniam dusuliui, sąlygojančiam II, III laipsnio gerklų stenozę, atliekama BK laterofiksacija (5 pav.) ar tracheostomija $[16,18]$.

\section{KOSULYS IR GERKLŲ SVETIMKŪNIAI}

Gerklų svetimkūniai taip pat gali sukelti kosulị [2] Maži svetimkūniai yra iškosimi, o didieji įstringa gerklų spindyje (6 pav.) ir sukelia įvairaus intensyvumo gerklų dirginimą ir kosulị. Priklausomai nuo pobūdžio ir lokalizacijos svetimkūniai iš gerklų šalinami ịvairiais būdais: gerklų žnyplèmis netiesioginès laringoskopijos metu; fibrobronchoskopu ar tiesioginès laringoskopijos metu. Kartais svetimkūniui pašalinti prireikia tracheostomos.

\section{KOSULYS IR IŠORINĖS KLAUSOMOSIOS LANDOS LIGOS}

Kadangi klajoklis nervas inervuoja išorinę klausomąją landą (IKL), ịvairūs šios srities dirgikliai gali sąlygoti refleksini kosuli $[1,2]$. Kosuli gali provokuoti IKL sieros ar epiderminis kamštis (7 pav.), svetimkūniai, lètinès ausies odos ligos: kontaktinis dermatitas, egzema, grybelinis otitas ar kaulinès išaugos. Sieros kamščiai linkę susidaryti esant priežastims, lemiančioms kramtymo sutrikimus; asmenims, nesimaudantiems vonioje ar saugojantiems ausis nuo vandens patekimo; neretai juos susidaryti skatina riebaus tipo oda, aktyvus IKL valymas.

Sieros kamščiai, svetimkūniai šalinami išplaunant IKL ar mikrochirurginiais instrumentais. Kaulinių išaugu atveju atliekamos operacijos. IKL odos ligos gydomos konservatyviai, medikamentini gydymą derinant su ligą skatinančio veiksnio šalinimu [19]. Neretai gydant IKL odos ligas praverčia dermatologo konsultacija.

\section{LĖTINIS KOSULYS IR VIRŠUTINIŲ KVĖPAVIMO TAKUৃ SINDROMAS}

Medicinos literatūroje šiuo klausimu tebevyksta intensyvios diskusijos. Pastarojo meto kosulio metodinès rekomendacijos ir kosulio epidemiologijos tyrimai rodo didelius lètinio kosulio etiologijos skirtumus įvairiose šalyse. Etiologiniai lètinio kosulio ryšiai su rinosinusitu (JAV vadinama užnosiniu varvejjimu/viršutinių kvėpavimo takų sindromu; JK - rinitu ar rinosinusitu, Japonijoje - sinubronchiniu sindromu) ir eozinofilinémis apatiniu kvėpavimo taku ligomis, yra painiausi ir gali vieni kitus slèpti [20].

Vadinamojo užnosinio varvejjimo sindromo (UVS) simptomai ir klinikiniai požymiai yra nespecifiški, todèl tiksliai diagnozuoti UVS sukeltą kosuli vien iš anamnezès ir klinikinio tyrimo neįmanoma. Tarptautiniai ekspertai rekomenduoja UVS sampratos atsisakyti ir vietoje jos vartoti terminą „viršutinių kvėpavimo takų kosulio sindromas“ [21]. Šis terminas apimtų įvairias nosies ir sinusų ligas, galinčias sukelti antrinị kosulį.

Kita vertus, otorinolaringologineje literatūroje pateikiami gana prieštaraujantys aptartajam iprastiniam požiūriui duomenys, t. y. teigiama, kad tik maža dalis pacientų, sergančių pūliniu rinosinusitu, skundžiasi kosuliu, jei nèra gretutinès krūtinès ląstos ligos. Nors nosies ligos gali būti svarbios lètinio kosulio etiologijoje, manoma, kad tai nėra tokia įprastinè priežastis, kaip buvo iki šiol nurodoma literatūroje. Tikètina, kad 
užnosinė sekrecija nėra adekvati kosulio priežastis, todèl terminą „užnosinio varvejjimo sindromas“ tais atvejais, kai lètini kosulí, spejjama, sukelia nosies liga, siūloma keisti terminu „rinosinusitas“ [22].

Klinikinèje praktikoje pacientai, besiskundžiantys kosuliu ir turintys nosies ligų simptomų, turètų būti siunčiami otorinolaringologo konsultacijos. Kolegialiai bendradarbiaujant būtų sèkmingiau sprendžiami lètinio kosulio diferencinès diagnostikos ir gydymo klausimai.

\section{CHRONIC COUGH: AN OTORHINOLARYNGOLOGIST'S APPROACH}

\section{RŪTA PRIBUIŠIENÉ, VIRGILIJUS ULOZAS DEPARTMENT OF OTOLARYNGOLOGY KAUNAS UNIVERSITY OF MEDICINE}

Key words: cough, GERD, laryngeal paralysis, rinosinusitis, diseases of external ear.

Summary. Chronic cough presents a rather complex entity; therefore establishment of etiology requires involvement of specialists of different medical areas. Otohrinolaryngologists enables to confirm or exclude various causes of chronic cough: laryngopharyngeal form of GERD, laryngeal paralysis and foreign bodies, diseases of external ear, rinosinusitis, upper airway cough syndrome. In many cases only collaboration of several specialists may warrant an efficient management of chronic cough.

\section{LITERATŨRA}

1. Undem BJ, Kollarik M. The role of vagal afferent nerves in chronic obstructive pulmonary disease. Proc Am Thorac Soc. 2005;2(4):355-60; discussion 371-2. Review.

2. Canning BJ. Anatomy and neurophysiology of the cough reflex: ACCP evidence-based clinical practice guidelines. Chest. 2006 Jan;129(1 Suppl):33S-47S

3. Jecker P, Orloff LA, Wohlfeil M, Mann WJ. Gastroesophageal reflux disease (GERD), extraesophageal reflux (EER) and recurrent chronic rhinosinusitis. Eur Arch Otorhinolaryngol. 2006 Jul;263(7):664-7.

4. Bartusch O, Finkl M, Jaschinski U. Aspiration syndrome: epidemiology, pathophysiology, and therapy. Anaesthesist. 2008 May;57(5):519-30 quiz 531-2. Review.

5. Book DT, Rhee JS, Toohill RJ, Smith TL. Perspectives in laryngopharyngeal reflux: an international survey. Laryngoscope. 2002 Aug;112(8 Pt 1):1399-406.

6. Pribuisiene $R$, Uloza $\mathrm{V}$, Jonaitis L. Typical and atypical symptoms of laryngopharyngeal reflux disease. Medicina (Kaunas). 2002;38(7):699-705. Lithuanian.

7. Dent J., Brun J., Fendrick A.M., Fennerty M.B. Janssens, Kahrilas P.J., Lauritsen K., Reynolds J.C. Shaw M. Talley N.J. An evidence-based appraisal of reflux disease management - the Genval Workshop Report. Gut, 1999 vol.44 (suppl. 2):99-103.

8. Vakil N et Global Consensus Group. The Montreal definition and classification of GERD: a global evidence-based consensus. Am J Gastroenterol. 2006 Aug;101(8):1900-20;

9. Pribuišienè R., Uloza V. Lietuvos otorinolaringology žinios apie GERL laringofaringines formos diagnostiką ir gydymą. Otorinolaringologijos aktualijos. 2008,1: 41-3.

10. Pribuišienè R, Uloza V, Šiupšinskiene N, Butkus E, Kupčinskas L. Suaugusiu asmeny gastroezofaginio refliukso ligos laringofaringinès formos diagnostika. Lietuvos klinikinès praktinès nuorodos. Medicina (Kaunas). 2007;43(6):508-15. Review. Lithuanian.

11. Šiupšinskiene $N$, Uloza $V$, Pribuišienè $R$, Butkus $E$, Kupčinskas $L$.

Šiuolaikinis požiūris ị gastroezofaginio refliukso ligos gydymą. Lietuvos suaugusiuju gydymo klinikinès praktinès nuorodos. Medicina (Kaunas). 2007:43(10):832-9. Review. Lithuanian.

12. RH.Poe, MC Kallay, Chronic Cough and GERD, Chest 2003, 123, 3:679684

13. Koufman J.A. Gastroesophageal reflux and voice disorders. In Rubin et all. Diagnosis and treatment of Voice Disorders, Chapter 11, New-York: Igaku-Shoin, 1995.

14. Zentilin P. et all. Reassessment of the diagnostic value of histology in patients with GERD, using multiple biopsy sites and an appropriate control group. Am J Gastroenterol. 2005 Oct; 100(10):2299-306.

15. Koufman JA et al. Laryngopharyngeal reflux: position statement of the committee on Speech, Voice and Swalowing Disorders of the American Academy of Otolaryngology-Head and Neck surgery. Otolaryngol Head Neck Surg 2002, 127:32-5

16. Uloza V. Gerklu ligu atlasas. Vilnius: Mokslas; 1986.

17. Uloza V, Pribuisiene R, Saferis V. Multidimensional assessment of functional outcomes of medialization thyroplasty. Eur Arch Otorhinolaryngol. 2005 Aug;262(8):616-21.

18. Uloza V, Bal'siavichius K. Surgical treatment of bilateral laryngeal paralysis by lateral fixation of the vocal fold. Vestn Otorinolaringol. 1998;(6):247. Russian.

19. Pribuišienè R. Ausu sieros kamščiai. Lietuvos bendr. praktikos gydytojas 2004, 8: 505-7.

20. Niimi A. Geography and cough aetiology. Pulm Pharmacol Ther 2007;20(4):383-7.

21. Pratter MR. Chronic upper airway cough syndrome secondary to rhinosinus diseases (previously referred to as postnasal drip syndrome) ACCP evidence-based clinical practice guidelines. Chest. 2006 Jan;129(1 Suppl):63S-71S

22. O'Hara J, Jones NS. Post-nasal drip syndrome": most patients with purulent nasal secretions do not complain of chronic cough. Rhinology. 2006 Dec;44(4):270-3. 